\title{
Sosyal medya kullanıcılarına sağlanan All-on-4 dental implant sistemi hakkındaki bilgilerin yararlılığı
}

\author{
Özge Özdal Zincir (iD \\ Ağız, Diş ve Çene Cerrahisi Anabilim Dalı, \\ Diş Hekimliği Fakültesi, İstanbul Gelişim Üniversitesi, İstanbul, \\ Türkiye \\ Özet
}

AmAÇ: Bu çalışmanın amacı, diş hekimliğinde sıklıkla tercih edilen All-on-4 dental implant sistemi hakkındaki bilgilerin yer aldığı YouTube ${ }^{\mathrm{TM}}$ videolarını inceleyerek bilgilerin yararııı̆ıını ve içeriğini değerlendirmektir.

GeReç Ve Yöntem: 'All-on-4 dental implant' anahtar kelimeleriyle yapılan YouTube ${ }^{\mathrm{TM}}$ video taramasında ilk 150 video izlenerek değerlendirmeye alındı. Analiz kriterlerine uymayan $\mathbf{7 0}$ video değerlendirme dışı bırakılarak geriye kalan 80 videonun analizi yapıldı. Analizi yapılan tüm videoların bilgi içeriklerine göre 9 puan üzerinden yararlılık skorları belirlendi: 0-2 puan aralığındakiler yetersiz (kod 0), 3-5 puan aralığındakiler orta (kod 1) ve 6-9 puan aralığındakiler mükemmel (kod 2). Videoların süresi, izlenme sayısı, beğeni sayısı, beğenmeme sayısı ve yorum sayısı gibi demografik bilgileri kaydedildi. Tüm videolar yüklenme kaynağına (sağlık uzmanları, sağlık şirketi ve bilgilendirme web sitesi, bireysel kullanıcı) ve video tipine (hasta deneyimi, eğitsel) göre sınıflandırıldı. İstatistiksel analiz için Anova, Kruskal-Wallis testi, ki-kare testi ve Pearson-Spearman testi kullanılarak anlamlılık düzeyi $p<0.05$ olarak belirlendi.

BULGULAR: Videoların yararlılık skorları ortalaması 0.45 bulundu. Videoların yararlılık skorları ile demografik bilgileri karşılaştırıldığında sadece video süresi ile aralarında anlamlı bir ilişki olduğu bulundu ( $p=0.002)$. Yararlılık skoruyla izlenme oranı arasında anlamlı bir ilişki yoktu $(p=0.522)$. Video tipleri ile yararlılık skoru arasında anlamlı bir ilişski vardı ve bu anlamlılık eğitsel videolar lehineydi $(p=0.022)$. Ayrıca etkileşim indeksi ile yükleme kaynağı arasında da anlamlı bir ilişki vardı ve bireysel kullanıcı lehineydi $(p=0.008)$.

Sonuç: All-on-4 dental implant sistemi hakkındaki videoların yararılığı kısıtı bulunmuştur. Bu tür videoların konunun uzmanları tarafından denetlenmesi gerektiği düşünülmektedir.

Makale gönderiliş tarihi: 7 Nisan 2020; Yayına kabul tarihi: 19 Ekim 2020 * Iletișim: Dr. Özge Özdal Zincir, Istanbul Gelișim Üniversitesi, Diş Hekimliğ Fakültesi, Ağız, Diş ve Çene Cerrahisi Anabilim Dalı, İstanbul, Türkiye E-posta: ozgeozdalzincir@gmail.com
AnAhtar Kelimeler: Diş implantı; diş protezi; sosyal medya

KaYNAK GöstermeK İçin: Özdal Zincir Ö. Sosyal medya kullanıcılarına sağlanan All-on-4 dental implant sistemi hakkındaki bilgilerin yararlılığı. Acta Odontol Turc 2021;38(2):35-41

EDiтöR: Işıl Çekiç Nagaş, Gazi Üniversitesi, Ankara, Türkiye

YAYıN HAKKI: @ 2021 Özdal Zincir. Bu eserin yayın hakkı Creative Commons Attribution License ile ruhsatlandırılmıştır. Sınırsız kullanım, dağıtım ve her türlü ortamda çoğaltım, yazarlar ve kaynağın belirtilmesi kaydıyla serbesttir.

FinANSAl Destek: Bulunmamaktadır.

ÇıKAR ÇATIŞMASI: Bulunmamaktadır.

[The abstract in English is at the end of the manuscript]

\section{Giriş}

Dental implantlar, parsiyel ya da tam dişsizlik olgularında oral rehabilitasyon için sıklıkla kullanılmaktadır. ${ }^{1}$ Özellikle tam dişsiz hastaların, total protezlerindeki retansiyon ve stabilizasyon eksikliği gibi sebeplerle memnuniyetsizliklerinin dental implant destekli sabit protezlerle giderilmesiyle oldukça konforlu bir tedavi sağlanmaktadır. ${ }^{2}$ Fakat çoğu zaman tam dişsiz hastaların dental implant destekli protez ile rehabilitasyonu sırasında bazı engelleyici faktörlerle karşılaşılabilir. Bunlar; posterior bölgedeki kemiğin kalitesindeki düşüklük, diş çekimi sonrası alveol kretlerde gerçekleşen rezorpsiyon, maksiller sinüs tabanının kret tepesine doğru genişlemesi olarak sıralanabilir. ${ }^{3,4}$ Bu engelleyici faktör, sinüs greftleme gibi ileri cerrahi prosedürlerle ya da uzun kantileverli protezlerle elimine edilmeye çalışımaktadır. ${ }^{5-7}$ Fakat uzun kantilever, implantta aşırı stres birikimine, sinüs greftleme prosedürü de tedavi süresinin uzamasına ve ekstra maliyete sebep olmaktadır. ${ }^{8}$ Tüm bu sorunları elimine edebilmek için Malo ve ark. ${ }^{9}$ dört adet dental implantın immediat yükleme esasına dayanan All-on-4 (Nobel BioCare AG, Kloten, İsviçre) isimli tedavi protokolünü gündeme getirmişlerdir.

All-on-4 prosedüründe iki dental implant anterior bölgeye düz ve birbirine paralel, distaldeki iki dental implant ise maksimum $45^{\circ}$ olacak şekilde eğimli yerleştirilir. Protetik restorasyon sırasında açılı implantlar için açılı multiunit abutment kullanılmaktadır. ${ }^{10} \mathrm{Bu}$ prosedür 
ile kantilever uzunluğu azaltılarak, implant-kemik arayüzündeki stres birikimi ve kemik rezorpsiyon riski de azaltılmış olmaktadır. ${ }^{11}$

Geleneksel olarak, sağlık uzmanlarının ve organizasyonlarının hastalara sağlıkla ilgili bilgileri sağlama sorumlulukları bulunmaktadır. Son yıllara bakıldığında, internetin hayatımızda büyük yer edinmesi, erişebilme kolaylığı, hastaların bilgi edinme konusundaki tercihleri ve profesyonel sağlık danışmanlığı ile karşılaştırıldığında maliyetin azalması gibi nedenlerle medikal ve dental bilgi elde etme amacıyla internet kullanımı günümüzde oldukça popüler hale gelmiştir. Bilgi elde etmenin yanısıra hastalıklarının teşhisi ve tedavisini bulmak amacıyla da internet hastalar tarafından sıklıkla kullanılmaktadır. ${ }^{12}$

YouTube $^{\mathrm{TM}}$ (San Bruno, CA, ABD), ücretsiz video paylaşımları için 2005 yılında kurulmuş ve son yılların Google $^{T M}$ isimli web sitesinden sonra gelen 2. en popüler web sitesidir. ${ }^{13}$ YouTube ${ }^{\mathrm{TM}}$ videoları, hasta eğitimi ve sağlığın geliştirilmesi amacıyla birçok sağlık branşı tarafından kullanılmaktadır. ${ }^{14-16}$

YouTube $^{\text {TM }}$ videoları objektif değerlendirilen videolar olmadığı için izleyiciler, doğru olmayan ya da yanıltıcı bilgilerle karşılaşılabilmektedir. Bu çalışmadaki amacımız, günümüzde sıklıkla uygulanan All-on-4 dental implant prosedürü ile ilgili YouTube ${ }^{\mathrm{TM}}$ videolarındaki bilgilerin yararlılığını ve içeriğini değerlendirmektir.

\section{GeREÇ VE YönTEM}

\section{YouTube $^{\mathrm{TM}}$ videolarının taranması}

'All-on-4 dental implant' anahtar kelimeleri arama butonuna yazılarak 17 Mart 2020 tarihinde yapılan YouTube $^{\text {TM }}$ videoları aramasında YouTube ${ }^{\mathrm{TM}}$ kullanıcılarının ilk 60 ila 200 videoyu izlediği fakat bu kullanıcıların büyük çoğunluğunun genellikle sadece ilk 30 videoyu seyrettiği belirlendi. ${ }^{17} \mathrm{Bu}$ çalışmada da arama sonrası ilk 150 video izlenerek analiz edildi.

\section{Videoların seçimi}

İzlenen videoların değerlendirilmesinde, İngilizce veya Türkçe olmayan, ses ve başlık içermeyen, tekrarlanan, içeriği konuyla ilgisiz olan videolar ve reklamlar değerlendirme dışı bırakıldı (Şekil 1).

\section{Videoların analizi}

İzlenen videoların 80 tanesi analiz için uygun bulundu. Analizi yapılan her bir videonun demografik özellikleri olan; izlenme sayısı (videonun web sitesine yüklenme tarihinden itibaren kullanıcılar tarafından görüntülenme sayısı), toplam video süresi (videonun dakika ve saniye türünden süre miktarı), videoya yapılan yorum sayısı (videonun web sitesine yüklenme tarihinden itibaren kullanıcılar tarafından oluşturulan, videonun 'yorum' kısmındaki sayı), beğenme ve beğenmeme sayısı (videonun web sitesine yüklenme tarihinden itibaren kullanıcılar tarafından beğenme ya da beğenmeme butonuna basılarak oluşturulan sayılar), yüklenme tarihi (videonun web sitesine yüklenme tarihi) ve ülke orijini (videonun yüklendiği ülke) kaydedildi. İzleyicilerin etkileşimi, etkileşim indeksi ([beğenme sayısı-beğenmeme sayısı] / toplam izlenme sayısı $\times 100$ ) ve izlenme oranı (izlenme sayısı / yüklendikten sonraki gün sayısı × 100) formüllerine göre hesaplandı. ${ }^{18}$

Her video yüklenme kaynağına göre; sağlık uzmanı (diş hekimleri, çene cerrahları, protez uzmanları, protez teknikerleri vb.), sağlık şirketi ve bilgilendirme web sitesi (dental klinikler, dental implant firmaları vb.), bireysel kullanıc (hastalar veya hasta yakınları) olarak sınıflandırılmakla birlikte video tipleri de eğitsel ve hasta deneyimi olarak kategorize edildi. Ayrıca video içerikleri; tanım, endikasyonlar, kontrendikasyonlar, avantajlar, cerrahi prosedür içeriği, protez prosedür içeriği, komplikasyonlar, prognoz-sağkalım ve maliyet belirteçlerini içerip içermemesi açısından değerlendirildi. ${ }^{19-21}$ Her bir içerik belirteci 1 puan olarak skorlanıp, toplam puan 9 üzerinden hesaplandı. 0-2 puana sahip videolar yararlılık skoruna göre yetersiz,

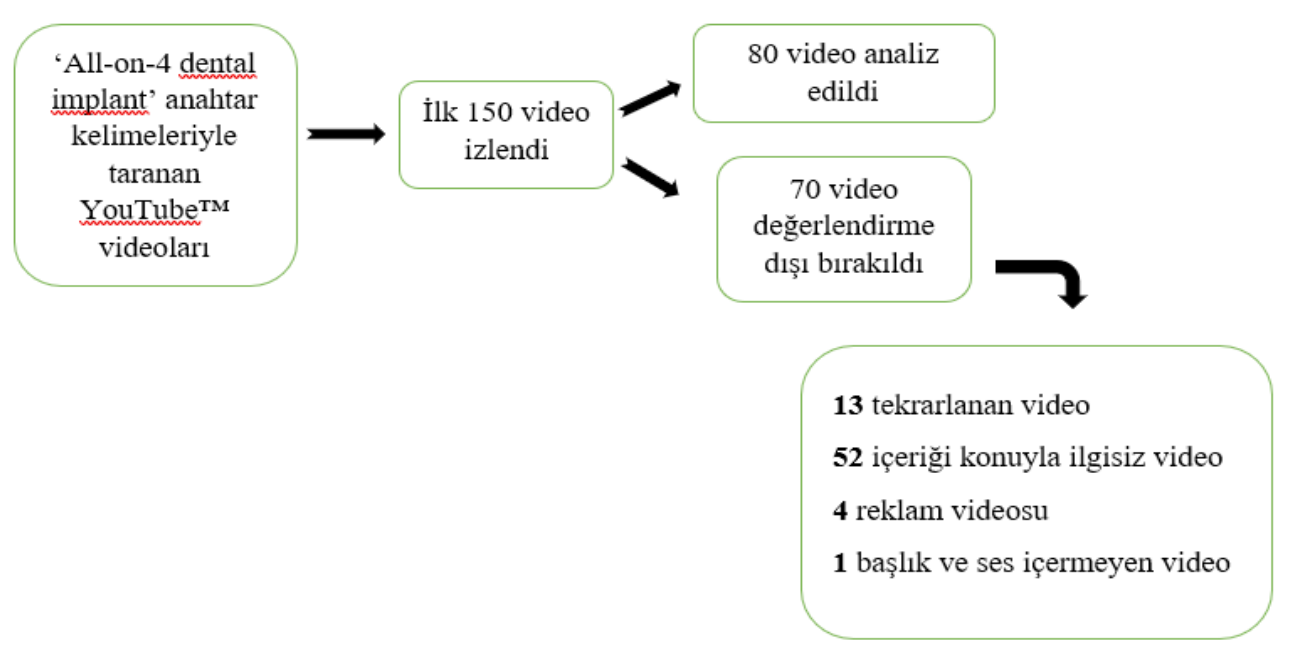




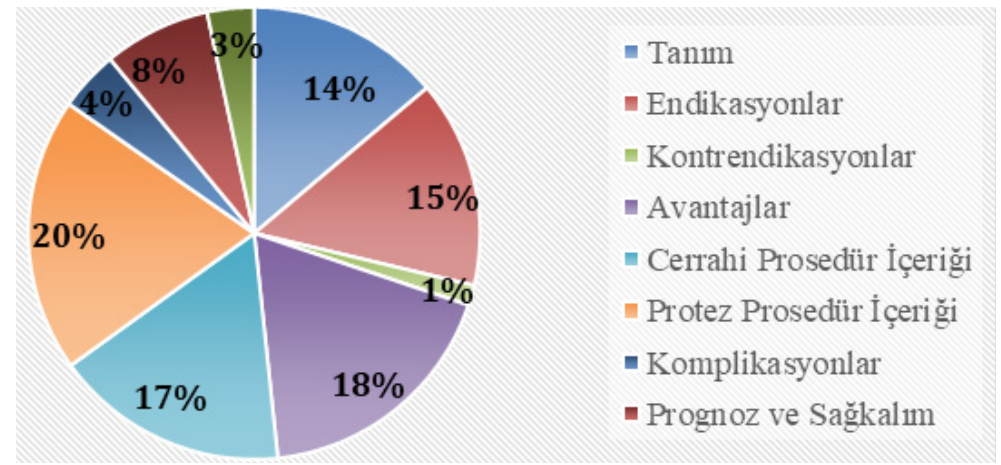

Şekil 2. Analizi yapılan videoların içerdikleri belirteçlerin oranı

3-5 puana sahip videolar yararlılık skoruna göre orta ve 6-9 puana sahip videolar ise yararlılık skoruna göre mükemmel olarak değerlendirildi. Yararlılık skoruna yetersiz seviye olarak değerlendirilenler 0 , orta olarak değerlendirilenler 1 ve mükemmel olarak değerlendirilenler ise 2 rakamlarıla kodlanarak kaydedildi. Yetersiz yararlılık skoru; "Yetersiz kalite ve akıştaki videolarda bazı bilgilerin listelenmesine rağmen çoğu bilginin eksik olması nedeniyle eğiticilik seviyesi düşüktür" olarak değerlendirildi. Orta yararlııık skoru; "Orta kalite ve akıştaki videolarda bazı önemli konuların tartışılıp, bazılarına yetersiz değinilmesi nedeniyle eğiticilik seviyesi orta düzeydedir" olarak değerlendirildi. Mükemmel yararlılık skoru ise "Mükemmel kalite ve akıştaki videolarda yeterli ve doğruluğu kesin bilgiler bulunmakta olduğundan dolayı eğiticiliği yüksek seviyededir" şeklinde değerlendirildi. ${ }^{17}$

Yanlılı̆ı azaltmak için her video, diş hekimi olan iki araştırmacı tarafından izlenerek değerlendirildi.

\section{İstatistiksel analiz}

Sürekli değişkenleri tanımlamak için deskriptif istatistikler kullanıldı. Kategorik değişkenleri tanımlama için frekans (n) ve yüzde (\%) değerleri kullanıldı. Normal dağılıma uygunluk göstermeyen ikiden fazla gruba ait sürekli değişkenlerin karşılaştırması Kruskal-Wallis testi ile yapıldı. Anlamlı bulunan değişkenlere ilişkin çoklu karşılaştırma analizi Mann-Whitney $U$ testi ile yapılmış olup, Bonferroni düzeltmesi kullanıldı. Kategorik değişkenler arasındaki ilişkinin incelenmesi amacıyla Fisher Exact test istatistiği kullanıldı. Araştırmacılar arasındaki uyum, kappa skoru ile hesaplandı. İstatistiksel anlamIılık düzeyi 0.05 olarak belirlendi. İstatistiksel analizler için IBM SPSS Statistical Software programında (version 21; IBM, Armonk, NY, ABD) yapıldı.

\section{BULGULAR}

\section{Videoların yüklenme kaynağı ve tipi}

İlk 150 video belirlenen analiz ölçütlerine göre uygunluk açısından değerlendirildi. Bu videoların 70 tanesi uygunluk kriterleri dışında olduğu için analiz grubuna dahil edilmedi (Şekil 1). Geriye kalan 80 video analiz edilerek yüklenme kaynağına göre sınıflandırıldı. Bu videoların \%43.75'inin $(n=35)$ sağlık uzmanları tarafından, \%48.75'inin ( $n=39$ ) sağlık şirketi ve bilgilendirme web sitesi tarafından ve \%7.5'inin $(n=6)$ bireysel kullanıcılar tarafından yüklenmiş olduğu görüldü. Ayrıca videolar tiplerine göre; \%17.5'i $(n=14)$ hasta deneyimi ve \%82.5'i ( $n=66)$ eğitsel videolar olarak sınıflandırıldı.

\section{Video süreleri, izlenme sayısı ve etkileşim indeksi}

Videoların ortalama süresi 6 dakika 50 saniye (en az süre 10 saniye, en fazla süre 60 dakika 9 saniye) ve izlenme sayısı ortalaması 114,279 idi (en az izlenme sayısı 62, en fazla izlenme sayısı 1,770,325). İzleyicilerin etkileşimi ise 0.7 etkileşim indeksi ortalamasına (en az 0.00 en fazla 5.22 beğenme sayısı ortalaması 1,282 , beğenmeme sayısı ortalaması 47) göre genel olarak pozitifti.

\section{Videoların menşei}

Çalışmadaki videoların çoğu Amerika Birleşik Devletleri (\%41.25; $n=33), \% 13.75$ 'i ( $n=11)$ Avustralya, \%7.5'i $(n=6)$ Kanada, \%6.25'i $(n=5)$ İngiltere, \%25'i $(n=20)$ diğer ülkeler (Almanya, Brezilya, Hollanda, İspanya, İsrail, Singapur, Şili, Tayland, İsveç, İsviçre, Meksika, Portekiz) orijinli olmakla birlikte, \%6.25'inin $(n=5)$ ülke orijini belirsizdi.

\section{Yararlılık skoru ve içerik belirteçleri}

Yararlılık skoruna göre kodlama yapılan videoların aritmetik kod ortalaması ' 0.45 ' olarak bulundu. Analizi yapılan videoların içerik belirteçleri; tanım \%14 ( $n=29)$, endikasyonlar \%15 ( $n=31)$, kontrendikasyonlar \%3 $(n=1)$, avantajlar \%18 $(n=38)$, cerrahi prosedür içeriği $\% 17(n=35)$, protez prosedür içeriği \%20 $(n=41)$, komplikasyonlar \%4 ( $n=9)$, prognoz-sağkalım \%8 $(n=16)$ ve maliyet \%3 ( $n=7)$ olarak hesaplandı (Şekil 2).

\section{Yararlılık skoru ile demografik özelliklerin karşılaş- tırılması}

Analizi yapılan videoların yararlılık skorları düzeylerine göre videolara ilişkin demografik özelliklerin ve video süresinin dağılımları incelendiğinde, video süresi dağılımlarının aynı düzeyde olmadığı (Kruskal-Wallis, $p=0.002$ ), diğer demografik özelliklerin dağılımlarının ise video yararlılık skorlarının düzeylerine göre farklılaşmadığı söylenebilir. Post-hoc ikili karşılaştırma sonuçları incelendiğinde yetersiz ve mükemmel, orta ve 
Tablo 1. Videoların yararlıık skoru ile ortalama demografik bilgilerinin karşıllaştırılması (Ortalama \pm Standart sapma)

\begin{tabular}{|c|c|c|c|c|}
\hline & Yetersiz $(n=48)$ & Orta $(n=28)$ & Mükemmel $(n=4)$ & p-değeri ${ }^{1}$ \\
\hline $\begin{array}{l}\text { Video süresi } \\
\text { (dakika) }\end{array}$ & $5.3 \pm 7.5$ & $6.3 \pm 4.3$ & $28.4 \pm 22.1$ & 0.002 \\
\hline İzlenme sayısı & $126,030 \pm 353,114$ & $102,899 \pm 189,273$ & $52,915.5 \pm 83,060$ & 0.741 \\
\hline Beğenme sayısı & $1,776.2 \pm 10,806$ & $593.4 \pm 1,441$ & $168.7 \pm 226$ & 0.301 \\
\hline Beğenmeme sayısı & $52.2 \pm 210.5$ & $41.7 \pm 91.4$ & $15 \pm 17.8$ & 0.244 \\
\hline Yorum sayısı & $285.1 \pm 1779.6$ & $71.4 \pm 210$ & $1.2 \pm 1.9$ & 0.412 \\
\hline \multicolumn{5}{|c|}{ Post-hoc ikili karşılaştırma sonuçları } \\
\hline & Yetersiz-orta & Yetersiz-mükemmel & Orta-mükemmel & \\
\hline $\begin{array}{l}\text { Video süresi } \\
\text { (dakika) }\end{array}$ & 0.074 & $<0.001$ & 0.002 & p-değeri ${ }^{2}$ \\
\hline
\end{tabular}

${ }^{1}$ Kruskal-Wallis Testi, ${ }^{2}$ Mann-Whitney U test

mükemmel düzeylere göre yararlılık skorlarının dağıIımlarının farklılaştığı ve mükemmel yararlılık düzeyinde video süresi ortalamasının diğerlerine göre anlamlı düzeyde yüksek olduğu söylenebilir (Mann-Whitney $U$, $p<0.016$ Bonferroni düzeltmesi) (Tablo 1).

Yararlılık skoru ile etkileşim indeksinin, izlenme oranının ve yükleme kaynağının karşılaştırılması

Videoların yararılıık skorları düzeylerine göre etkileşim indeksi (Kruskal-Wallis $p=0.349$ ), izlenme oranı (Kruskal-Wallis $p=0.652$ ) ve yükleme kaynağı (Fisher Exact $p=0.805$ ) dağılımlarının aynı düzeyde olduğu; yararlılığın yetersiz, orta ve mükemmel düzeylerinde benzer dağılım gösterdikleri söylenebilir (Tablo 2).

Yükleme kaynağı ile izlenme oranının ve etkileşim indeksinin karşılaştırılması

Yükleme kaynaklarına göre izlenme oranlarının benzer düzeyde olduğu söylenebilirken (Kruskal-Wallis $p=0.069$ ); yükleme kaynaklarına göre etkileşim indeksi dağılımının ise benzer düzeyde olmadığı görüldü (Kruskal-Wallis $p=0.008$ ). Post-hoc ikili karşılaştırma sonuçları incelendiğinde sağlık uzmanı ile bireysel kullanıcı, sağlık şirketi ve bilgilendirme web sitesi ve bireysel kullanıcı düzeylerinin etkileşim indeksi dağılımı açısından farklılaştığı ve bireysel kullanıcı etkileşim indeksi ortalamasının diğerlerine göre anlamlı düzeyde yüksek bulunduğu söylenebilir (Mann-Whitney $U$, $p<0.016$ Bonferroni düzeltmesi) (Tablo 3).

\section{Araştırmacılar arasındaki uyum}

Araştırmacılar arasındaki Kappa uyum katsayısı 0.83 olarak hesaplandı.

\section{TARTIŞMA}

Posterior maksilla ve mandibulada rezorpsiyon sonucu geleneksel dental implant cerrahisi uygulamalarını zorlaştıran anatomik ve kemik kalitesi gibi faktörler nedeniyle, Malo ve arkadaşlarının ${ }^{22,23}$ geliştirdiği All-on-4 dental implant sistemi günümüzde popüler olmuş, uzun dönem başarısı kanıtlanmış bir tedavi prosedürüdür. Bu tip vakalarda, All-on-4 prosedürü haricinde sabit bir protez rehabilitasyonu gerçekleştirebilmek için rezorbe posterior bölgelere kemik greftleme uygulamaları gerekmektedir. Bu uygulamalar ise; birden çok oral cerrahi işlem içermesi, komplikasyon risklerinin daha yüksek olması, daha fazla tedavi süresi ve maliyet gerektirmesi, hasta tarafından kabul edilebilirliğin daha düşük olması gibi kısıtlamaları da beraberinde getirdiği için All-on-4 sistemi popülerliğini ve güncelliğini korumaktadır. ${ }^{24,25}$

Tablo 2. Yararlıık skorlarıyla etkileşim indeksi, izlenme oranı ve yükleme kaynağı arasındaki ilişkilerin karşıllaştırılması (Ortalama \pm Standart sapma)

\begin{tabular}{|c|c|c|c|c|c|c|}
\hline & & $\begin{array}{c}\text { Yetersiz } \\
(n=48)\end{array}$ & Orta $(n=28)$ & $\begin{array}{l}\text { Mükemmel } \\
\quad(n=4)\end{array}$ & $\begin{array}{c}\text { Test istatistik } \\
\text { değeri }\end{array}$ & p-değeri \\
\hline \multicolumn{2}{|c|}{ Etkileşim indeksi } & $0.7 \pm 1.1$ & $0.8 \pm 0.9$ & $0.3 \pm 0.2$ & 2.104 & 0.349 \\
\hline \multirow{2}{*}{\multicolumn{2}{|c|}{ İzlenme oranı }} & $175 \pm 648.2$ & $203.5 \pm 453.1$ & $240.5 \pm 357$ & 0.857 & 0.652 \\
\hline & & n (\%) & n (\%) & n (\%) & & \\
\hline \multirow{3}{*}{$\begin{array}{l}\text { Yükleme } \\
\text { kaynağı }\end{array}$} & Sağlık uzmanı & $19(54.3)$ & $14(40.0)$ & $2(5.7)$ & \multirow{3}{*}{1.756} & \multirow{3}{*}{0.807} \\
\hline & $\begin{array}{l}\text { Sağlık şirketi ve } \\
\text { bilgilendirme web } \\
\text { sitesi }\end{array}$ & $24(61.6)$ & $13(33.3)$ & $2(5.1)$ & & \\
\hline & Bireysel kullanıcı & $5(83.3)$ & $1(16.7)$ & 0 & & \\
\hline
\end{tabular}


Tablo 3. Yükleme kaynakları ile etkileşim indeksi ve izlenme oranı arasındaki ilişkilerin karşılaştırılması (Ortalama \pm Standart sapma)

\begin{tabular}{|c|c|c|c|c|c|}
\hline & $\begin{array}{l}\text { Sağlık uzmanı } \\
(n=35)\end{array}$ & $\begin{array}{l}\text { Sağlık şirketi ve } \\
\text { bilgilendirme web sitesi } \\
(n=39)\end{array}$ & $\begin{array}{c}\text { Bireysel kullanıcı } \\
(n=6)\end{array}$ & $\begin{array}{c}\text { Ki-kare test istatistik } \\
\text { değeri }\end{array}$ & p-değeri ${ }^{1}$ \\
\hline Etkileşim indeksi & $0.6 \pm 0.7$ & $0.6 \pm 1$ & $1.8 \pm 1.7$ & 9.582 & 0.008 \\
\hline İzlenme oranı & $148.2 \pm 388.6$ & $99.3 \pm 299.3$ & $855.8 \pm 166.4$ & 5.338 & 0.069 \\
\hline \multicolumn{6}{|c|}{ Post-hoc ikili karşılaştırma sonuçları } \\
\hline & $\begin{array}{c}\text { Sağlık uzmanı- } \\
\text { sağlık şirketi ve } \\
\text { bilgilendirme web } \\
\text { sitesi }\end{array}$ & $\begin{array}{c}\text { Sağlık uzmanı-bireysel } \\
\text { kullanıcı }\end{array}$ & $\begin{array}{c}\text { Sağlık şirketi ve } \\
\text { bilgilendirme web } \\
\text { sitesi-bireysel } \\
\text { kullanıcı }\end{array}$ & \multicolumn{2}{|c|}{ p-değeri² } \\
\hline Etkileşim indeksi & 0.239 & 0.005 & 0.003 & & \\
\hline
\end{tabular}

${ }^{1}$ Kruskal-Wallis testi, ${ }^{2}$ Mann-Whitney U test

Günümüzde sosyal medya ve video paylaşım web siteleri, site kullanıcıları tarafından paylaşılan videolar sayesinde sağlık konuları hakkında topluma bilgi sağlaması açısından oldukça sık kullanılan araçlar haline gelmiştir. ${ }^{26}$ YouTube ${ }^{\mathrm{TM}}$ da günümüzün en popüler ve sağlığın birçok farklı konusunda videolarının bulunduğu bir sosyal medya video paylaşım sitesidir. ${ }^{13-16}$

All-on-4 dental implant sisteminin incelendiği bu çaIışmada, analizi yapılan videoların toplam ve ortalama görüntülenme sayısı, videolara yapılan toplam yorum sayısı, videoların ortalama beğeni sayısı gibi parametrelerin yüksek olması bu tedavi prosedürünün popülerliğini açıklayabilen bir sebep olabilir.

Nervus alveolaris inferior ve sinüs maksillaris gibi anatomik engellere rağmen, distaldeki eğimli iki dental implant sayesinde protetik restorasyonun kantilever uzunluğunun azaltılması, Malo ve arkadaşlarını ${ }^{9,27}$ yaptıkları çalışmalarda hastaların hayat kalitesinin arttığını göstermekle birlikte, Algiardi ve arkadaşlarının ${ }^{28}$ yaptıkları bir çalışmada da kemik greftleme prosedürlerinden kaçınarak zaman ve maliyetten tasarruf edildiğinin belirtilmesi gibi durumlar bu tedavi şeklinin en önemli avantajlarını oluşturmaktadır. Eğiticilik konusunda önemli bir yere sahip olan bu tip avantajlar, çalışmamızda analizi yapılan videoların $\% 18$ 'inde konu içeriği olarak işlenmiştir. Ayrıca analizi yapılan videoların \%17'sinde tedavi sisteminin cerrahi prosedürü ve \%20'sinde de protetik prosedürü içerik olarak bulunmaktadır.

Lena ve arkadaşlarının ${ }^{29}$ yaptığı bir çalışmaya paralel olarak bizim çalışmamızda da konu içeriği bakımından zenginlik ölçümü açısından yapılan sınıflandırmada, mükemmel yararlılık skoruna sahip videoların süresi, orta ve yetersiz yararlılık skoruna sahip olan videolara kıyasla daha uzundur. Bu sonuç, bilgi içeriği fazla olan videoların sürelerinin de fazla olabileceğini göstermektedir.

Analizi yapılan videoların yüklenme kaynağı ile yararlıık skoru arasındaki ilişkiye bakıldığında, sağlık uzmanları tarafından yüklenen videoların \%54.3'ünün yetersiz, \%40'ının orta ve \%5.7'sinin ise mükemmel yararlıık skoruna sahip olduğu belirlenmiştir. Literatüre bakıldığında ise sağlık uzmanları tarafından yüklenen video içeriklerinin bireysel kullanıcılar tarafından yüklenen video içeriklerine oranla daha fazla ve bilgi kalitesinin daha yüksek olması, çalışmamızdaki bu sonucun beklenmedik olduğunu göstermektedir. ${ }^{30}$

Videoların yüklenme kaynağı ile etkileşim indeksi arasındaki ilişkide, bireysel kullanıcıların etkileşim indeksi diğerlerine göre yüksektir. Fakat bireysel kullanıcı kaynaklı videoların yararlılık skorunun diğerlerine oranla yetersiz olması, videoların beğeni sayısıyla bilgi içeriğinin yoğunluğu arasında doğru orantı olmadığı sonucunu çıkarmaktadır. Bu sebeple bilgilenmek amaçlı izlenen bu videoların yararlııı düzeyinin, demografik bilgilerine bağlı olmadığı görülmektedir. İzlenme ya da beğenme sayısının bilgi sağlama düzeyinden bağımsız olduğu da söylenebilir.

Bu verilerin ışığında video popülerliğinin fazla olmasının, bilgilendirme ve yararılılık açısından değerlendirilmesinde ön planda tutulmaması gerektiği düşünülmektedir.

\section{SonUç}

All-on-4 dental implant sistemi hakkındaki bilgilerin değerlendirildiği bu çalışmadaki YouTube ${ }^{T M}$ videolarında, eğiticilik düzeyinin yetersiz ve özellikle sağlık uzmanları tarafından yüklenen videoların çoğunun bilgi içeriğinin düşük olması, sosyal medyanın bu konu hakkında izleyicilere eksik eğitim verebileceğini göstermektedir. Ayrıca bireysel kullanıcıların etkileşim indeksinin yüksek olması, hasta ve hasta yakınlarının paylaşımlarının kullanıcılar tarafından daha fazla tercih edilebildiğini belirtmektedir.

\section{TEŞEKKüR VE ANMA}

Araştırmanın istatistiksel analizleri Ali Zincir tarafından yapılmıştır. 


\section{KAYNAKLAR}

1. Giannobile WV, Lang NP. Are dental implants a panacea or should we better strive to save teeth? J Dent Res 2016;95:5-6.

2. Boven GC, Raghoebar GM, Vissink A, Meijer HJ. Improving masticatory performance, bite force, nutritional state and patient's satisfaction with implant overdentures: a systematic review of the literature. J Oral Rehabil 2015;42:220-33.

3. Chiapasco M, Zaniboni M. Methods to treat the edentulous posterior maxilla: implants with sinus grafting. J Oral Maxillofac Surg 2009;67:867-71.

4. Bhering CL, Mesquita MF, Kemmoku DT, Noritomi PY, Consani RL, Barão VA. Comparison between all-on-four and all-on-six treatment concepts and framework material on stress distribution in atrophic maxilla: a prototyping guided 3D-FEA study. Mater Sci Eng C Mater Biol Appl 2016;69:715-25

5. Malhotra AO, Padmanabhan TV, Mohamed K, Natarajan S, Elavia $U$. Load transfer in tilted implants with varying cantilever lengths in an all-on-four situation. Aust Dent J 2012;57:440-5

6. Baggi L, Pastore S, Di Girolamo M, Vairo G. Implant-bone load transfer mechanisms in complete-arch prostheses supported by four implants: a three-dimensional finite element approach. J Prosthet Dent 2013;109:9-21.

7. Patzelt SB, Bahat O, Reynolds MA, Strub JR. The all-on-four treatment concept: a systematic review. Clin Implant Dent Relat Res 2014;16:836-55.

8. Schwartz-Arad D, Herzberg R, Dolev E. The prevalence of surgical complications of the sinus graft procedure and their impact on implant survival. J Periodontol 2004;75:511-6.

9. Malò $\mathrm{P}$, Rangert B, Nobre M. "All-on-Four" immediate-function concept with Brånemark System implants for completely edentulous mandibles: a retrospective clinical study. Clin Implant Dent Relat Res 2003;5:2-9.

10. Maló P, Rangert B, Nobre M. All-on-4 immediate-function concept with Brånemark System implants for completely edentulous maxillae: a 1-year retrospective clinical study. Clin Implant Dent Relat Res 2005; 7:88-94

11. Saleh Saber F, Ghasemi S, Koodaryan R, Babaloo A, Abolfazli $\mathrm{N}$. The comparison of stress distribution with different implant numbers and inclination angles in all-on-four and conventional methods in maxilla: a finite element analysis. J Dent Res Dent Clin Dent Prospects 2015;9:246-53

12. Riordain $R N$, Hodgson $T$. Content and quality of website information on the treatment of oral ulcers. Br Dent J 2014:217:15.

13. Alexa 2020. The top 500 sites on the web. http://www.alexa.com/ topsites. Accessed 25 March 2020.

14. Kumar N, Pandey A, Venkatraman A, Garg N. Are video sharing web sites a useful source of information on hypertension? J Am Soc Hypertens 2014;8:481-90.

15. Altan Şallı G, Egil E. Are YouTube videos useful as a source of information for oral care of leukemia patients? Quintessence Int 2020;51:78-85

16. Hutchison CM, Cave V, Walshaw EG, Burns B, Park C. YouTube ${ }^{T M}$ as a source for patient education about the management of dental avulsion injuries. Dent Traumatol 2020;36:207-11.

17. Hegarty E, Campbell C, Grammatopoulos E, DiBiase AT, Sherriff $\mathrm{M}$, Cobourne MT. YouTube ${ }^{\mathrm{TM}}$ as an information resource for orthognathic surgery. J Orthod 2017;44:90-6.

18. Hassona Y, Taimeh D, Marahleh A, Scully C. YouTube as a source of information on mouth (oral) cancer. Oral Dis 2016;22:202-8.

19. Özdal Zincir Ö, Bozkurt AP, Gaş S. Potential patient education of YouTube videos related to wisdom tooth surgical removal. J Craniofac Surg 2019;30:481-4.

20. Pasaoglu Bozkurt A, Gaş S, Özdal Zincir Ö. YouTube video analysis as a source of information for patients on impacted canine. Int Orthod 2019;17:769-75.

21. Gaş S, Zincir ÖÖ, Bozkurt AP. Are YouTube videos useful for pa- tients interested in botulinum toxin for bruxism? J Oral Maxillofac Surg 2019;77:1776-83.

22. Maló $P$, de Araújo Nobre M, Lopes A, Ferro A, Botto J. The all-on-4 treatment concept for the rehabilitation of the completely edentulous mandible: a longitudinal study with 10 to 18 years of follow-up. Clin Implant Dent Relat Res 2019;21:565-77.

23. Maló $P$, de Araújo Nobre M, Lopes A, Ferro A, Nunes M. The Allon-4 concept for full-arch rehabilitation of the edentulous maxillae: a longitudinal study with 5-13 years of follow-up. Clin Implant Dent Relat Res 2019;21:538-49.

24. Schwartz-Arad D, Herzberg R, Dolev E. The prevalence of surgical complications of the sinus graft procedure and their impact on implant survival. J Periodontol 2004;75:511-6.

25. Aslan M. Maksillada açılı implantlar kullanılarak yapılan immediat yüklemenin kısa dönem sonuçları. Atatürk Üniv Diş Hek Fak Derg 2020;30:75-82.

26. Randeree E. Exploring technology impacts of Healthcare 2.0 initiatives. Telemed J E Health 2009;15:255-60.

27. Malo $P$, de Araújo Nobre M, Lopes A, Moss SM, Molina GJ. A longitudinal study of the survival of All-on-4 implants in the mandible with up to 10 years of follow-up. J Am Dent Assoc 2011;142:310-20.

28. Agliardi EL, Pozzi A, Stappert CF, Benzi R, Romeo D, Gherlone E. Immediate fixed rehabilitation of the edentulous maxilla: a prospective clinical and radiological study after 3 years of loading. Clin Implant Dent Relat Res 2014;16:292-302.

29. Lena $Y$, Dindaroğlu F. Lingual orthodontic treatment: a YouTube ${ }^{T M}$ video analysis. Angle Orthod 2018;88:208-14.

30. Strychowsky JE, Nayan S, Farrokhyar F, MacLean J. YouTube: a good source of information on pediatric tonsillectomy? Int J Pediatr Otorhinolaryngol 2013;77:972-5.

\section{The usefulness of information about All-on-4 dental implant system provided for social media users}

\section{Abstract}

OвJеctive: To evaluate the content and usefulness of information by examining YouTube ${ }^{\mathrm{TM}}$ videos that contain information about the All-on-4 dental implant system, which is often preferred in dentistry.

Materials AND Method: The first 150 YouTube $^{\mathrm{TM}}$ videos listed using the search phrase "All-on-4 dental implant" were watched and evaluated. Based on the analysis criteria, 70 videos were excluded from further evaluation and the remaining $\mathbf{8 0}$ videos were analyzed. A 9-point "Usefulness" score was developed according to the information content of the analyzed videos, in which 0-2 was poor (code 0), 3-5 was moderate (code 1), and 6-9 was excellent (code 2). Demographic data of the videos, such as duration, number of views, likes and dislikes, and comments, were evaluated. All videos were categorized according to upload source (healthcare professionals, healthcare company, information website or individual users) and video type (patient experience or educational). For statistical analysis, Anova, Kruskal-Wallis, chi-square, and PearsonSpearman tests were used and the significance was defined as $\mathrm{p}<0.05$.

RESULTS: The mean usefulness score of the videos was 0.45. In comparisons between usefulness score and demographic data of the videos, an association was 
found between the usefulness score and video duration $(p=0.002)$, but not with viewing rate $(p=0.522)$. Furthermore, we found a relationship between the usefulness score and video type, specifically with educational videos $(p=0.022)$. There was also an association between the interaction index and upload source, which is individual users $(p=0.008)$.
ConCLusion: The usefulness of information in the videos about the All-on-4 dental implant system available on YouTube $^{\mathrm{TM}}$ is of limited value. It is recommended that such videos are reviewed in advance by subject-matter professionals.

KEYWORDS: Dental implant; dental prosthesis; social media 